\title{
Genome-wide Scan of IQ Finds Significant Linkage to a Quantitative Trait Locus on $2 q$
}

\author{
M. Luciano, ${ }^{1,2}$ M. J. Wright, ${ }^{1}$ D. L. Duffy, ${ }^{1}$ M. A. Wainwright, ${ }^{1}$ G. Zhu $^{1}{ }^{1}$ D. M. Evans, ${ }^{1}$ \\ G. M. Geffen, ${ }^{1}$ G. W. Montgomery, ${ }^{1}$ and N. G. Martin ${ }^{1}$
}

Received 6 Feb. 2005-Final 20 June 2005

\begin{abstract}
A genome-wide linkage scan of 795 microsatellite markers (761 autosomal, $34 \mathrm{X}$ chromosome) was performed on Multidimensional Aptitude Battery subtests and verbal, performance and full scale scores, the WAIS-R Digit Symbol subtest, and two word-recognition tests (Schonell Graded Word Reading Test, Cambridge Contextual Reading Test) highly predictive of IQ. The sample included 361 families comprising 2-5 siblings who ranged in age from 15.7 to 22.2 years; genotype, but not phenotype, data were available for $81 \%$ of parents. A variance components analysis which controlled for age and sex effects showed significant linkage for the Cambridge reading test and performance IQ to the same region on chromosome 2, with respective LOD scores of 4.15 and 3.68. Suggestive linkage (LOD score $>2.2$ ) for various measures was further supported on chromosomes $6,7,11,14,21$ and 22 . Where location of linkage peaks converged for IQ subtests within the same scale, the overall scale score provided increased evidence for linkage to that region over any individual subtest. Association studies of candidate genes, particularly those involved in neural transmission and development, will be directed to genes located under the linkage peaks identified in this study.
\end{abstract}

KEY WORDS: Cognitive abilities; genome-wide linkage; IQ; reading ability; twins.

\section{INTRODUCTION}

Intelligence, as measured by Intelligence Quotient (IQ) tests and other cognitive ability scales, is one of the most heritable behavioural phenotypes ever studied (McClearn et al., 1997; Plomin, 1999). Cognitive abilities are complex traits, and as such, many genes of small effect size are hypothesised to contribute to their variation. Association studies aiming to find Quantitative Trait Loci (QTLs) influencing IQ have been relatively unsuccessful, due perhaps to the vast number of potential genes that may affect brain processes or our lack of knowledge of what these

\footnotetext{
${ }^{1}$ Queensland Institute of Medical Research, Herston, Brisbane, Australia.

2 To whom correspondence should be addressed at Queensland Institute of Medical Research, Herston, Brisbane, QLD, 4029, Australia. Tel.: +617-3362-0218; Fax: +617-3362-0101; e-mail: michelle.luciano@qimr.edu.au
}

might be. Some recent, positive findings from targeted candidate gene studies have found polymorphisms in the genes coding for brain-derived neurotrophic factor, prion protein, and succinatesemialdehyde dehydrogenase to be associated with normal variation in IQ, but these results await replication (Plomin et al., 2004; Rujescu et al., 2003; Tsai et al., 2004).

A wide-scale effort to find genes influencing IQ was initiated by Plomin and colleagues in 1994, who examined the association between 100 DNA markers in/near genes relevant to neural functioning in high and low IQ groups (respective mean IQs of 130 and 82) (Plomin et al., 1995). Significant allelic frequency differences between groups were found for various markers, although not all were replicated. Using eight of the most significant markers associated with general cognitive ability $(g)$, associations were confirmed 
that there was some overlap in genetic effects on specific abilities and $g$ (Petrill et al., 1996b). A more systematic approach was later taken by using a denser map of markers, subjects with a wider IQ range, and replication samples to reduce Type I errors; the first replicated association was between $g$ and the insulin-like growth factor-2 receptor (IGRF) gene (Chorney et al., 1998), although this did not generalise to an independent sample (2001). In a genomewide association analysis using 1842 markers, Plomin and colleagues (2001) found associations with 108 markers in the first stage of analysis (case-control DNA pooling), but none replicated to all five stages. It is obvious from these studies that genome-wide investigations will undoubtedly produce many false positive results, thus reinforcing the need for replication of identified genes.

An alternative, systematic approach to detect genes influencing IQ is to use a nonparametric linkage design. While this method lacks the power of an association analysis, it can implicate chromosomal regions that harbour genes (usually of moderate to large effect) for IQ without the requirement that the genetic markers be the functional polymorphisms or genes extremely close by (Vink and Boomsma, 2002). Furthermore, it has been shown that the clustering of QTLs of small effect in the same region can produce a linkage signal of relatively large effect (Legare et al., 2000; van Wezel et al., 1999; Yalcin et al., 2004). Like association analysis, though, replication of QTLs identified using whole genome methods is essential given the multiple testing of markers. A linkage approach is followed in the present paper and applied to IQ phenotypes in a sample of adolescent twins and their siblings. Any significant results from this analysis will of course assume greater importance upon their replication in independent samples, as has been the case with QTLs found for reading disability (e.g., Fisher et al., 2002). Upon replication, a bioinformatics search might identify candidate genes located under significant linkage peaks, and single nucleotide polymorphisms (SNPs) within these genes could be typed and tested for association with the traits of interest.

The Full scale of an IQ test measures a global cognitive ability that pervades diverse tests of cognition, including verbal, spatial, and perceptual speed tasks (Carroll, 1993; Gustafsson, 1984; Ward et al., 2000). While it is a reliable indicator of one's general cognitive ability, a prominent theory of intelligence separates verbal and non-verbal (or performance) abilities into two broad, albeit correlated, components of intelligence (Cattell, 1963; Horn and Cattell,
1966). Verbal ability draws on learnt knowledge and is influenced by education, culture and environmental experiences, whereas performance ability captures incidental learning influences and reasoning. The findings from behavioural genetic studies are somewhat aligned with this view in that verbal IQ shows a larger contribution to variation from the common environment than does performance IQ/visuo-spatial ability (Casto et al., 1995; Rietveld et al., 2000; Wainwright et al., 2004). Further distinction between verbal and performance abilities is provided by results which show independent verbal and performance genetic factors in addition to the general genetic cognitive factor (Luciano et al., 2004a; Petrill et al., 1996a; Rijsdijk et al., 1998). Specific genetic influences on individual IQ subtests tend to be significant, but small in magnitude (Luciano et al., 2003; Pedersen et al., 1994).

Following from the behavioural genetic findings that general, group and specific genetic factors contribute significantly to the variation of a cognitive trait, a genome-wide linkage analysis was performed for full scale IQ, verbal and performance scaled scores, and IQ subtest scores. It was expected that individual subtests within the same abilities domain (verbal/ performance) would show a greater overlap of potential linkage regions than subtests between domains due to their reliance on both a general and group genetic factor. Also, genetic linkage to word-recognition indices highly predictive of IQ (verbal more so than performance) was investigated. Linkage for these reading indices was hypothesised to coincide with regions important for IQ, especially verbal IQ, as they are neuropsychological indices of premorbid IQ. As these whole-word reading tests tap variance in reading ability independent of IQ (see Wainwright et al., 2004) it is possible that they will also show linkage to regions previously reported for reading phenotypes in dyslexic samples (e.g., Cardon et al., 1994; Fisher et al., 2002).

\section{METHOD}

\section{Sample}

A sub-sample of twins from an ongoing study of cognition in adolescence (see Wright et al., 2001) had been genotyped as part of an earlier study investigating melanoma risk factors (Zhu et al., 1999). This sample comprised $320 \mathrm{DZ}$ twin families (48 with one non-twin sibling, 10 with two non-twin siblings, 1 with three non-twin siblings) and $41 \mathrm{MZ}$ twin families (39 with one non-twin sibling, 2 with two non-twin siblings). Informed consent to jointly examine the 
cognitive and genotype data was obtained from participants and their parent/guardian if participants were younger than 18 years of age. The mean age of the twin sample at time of cognitive testing was 16.2 $( \pm 0.5)$ years, while siblings of twins were on average, $17.1( \pm 1.1)$ years. The age range of the sample was $15.7-22.2$ years.

\section{Zygosity and Genotyping}

Blood was obtained from twins, siblings and from $80 \%$ of parents for blood grouping and DNA extraction. Zygosity of same-sex twins was diagnosed using nine polymorphic DNA microsatellite markers (AmpF1STR Profiler Plus Amplification Kit, ABI) and three blood groups (ABO, MNS and Rh), giving a probability of correct assignment greater than $99.99 \%$. Genotyping was performed by two facilities, the Australian Genome Research Facility (AGRF, Melbourne) and the Centre for Inherited Disease Research (CIDR, Baltimore). In short, 796 microsatellite markers (761 on all autosomes; 34 on the $\mathrm{X}$ chromosome; and a pseudo-autosomal marker in the region of the $\mathrm{X}$ chromosome which was not used in this study) were typed at approximately equal intervals (average of $4.8 \mathrm{cM}$ ) across the entire genome, with locations determined from the sex-averaged deCODE map (Kong et al., 2002; Leal, 2003) and interpolation of unmapped markers. Marker heterozygosity ranged between 52.6 and $91.9 \%$. Details of the genotyping and data cleaning procedure, including information on the overlap between markers typed at the different facilities, are published elsewhere (see Zhu et al., 2004). In the present sample, both parental genotypes were available for 260 families, while one or neither parent was genotyped in 67 and 34 families, respectively. Parents were typed for between 228 and 784 markers (mean of $398 \pm 101$ ). For twins/siblings, the number of typed markers ranged from 211 to 790, with an average of 601 $( \pm 192)$ total markers.

\section{Cognitive Measures}

The cognitive assessments included IQ and word-recognition tests. The Multi-dimensional Aptitude Battery (MAB) assessed IQ and consisted of three verbal subtests (information, vocabulary, arithmetic) and two performance subtests (spatial, object assembly) which were computer administered and each timed at 7 minutes (Jackson, 1984, 1998). Raw scores of the subtests and scaled scores for verbal, performance and full IQ were examined. The digit symbol test (a subtest of the WAIS-R, Wechsler, 1981) was also administered and is a measure of perceptual speed (a performance measure). The word-recognition tests included the Cambridge Contextual Reading Test (Beardsall and Huppert, 1994; Nelson, 1982) and the Schonell Graded Reading Test (Schonell and Schonell, 1960) as described in Wainwright and colleagues (2004). The Cambridge test assesses the pronunciation of irregular words (which must be part of the reader's internal lexicon to be correctly pronounced) embedded within sentences, whereas the Schonell consists of a list of regular (which can be pronounced using grapheme-phoneme conversion rules) and irregular words. The digit symbol and word recognition tests were introduced to the test battery roughly four months after the study commenced and thus have fewer data points than the MAB IQ. All variables with the exception of the Schonell reading test-transformed by a reverse, logarithmic function - were normally distributed.

\section{Descriptive Analyses}

Inter-correlations among the IQ subtests and reading measures were obtained to assess the strength of associations between the varied measures. A principal components analysis was also performed to examine these associations, although the primary reason for this analysis was to derive the number of orthogonal factors present in the data, so that a Bonferroni correction for multiple testing could be made to the empirical $p$-values (see below). This method of correcting for correlated traits has been used in other studies (e.g., De Koning et al., 1998; Spelman et al., 1996) and provides a less conservative alpha level than a full Bonferroni correction. SPSS 12.0.2 (1989-2003) was used for these analyses.

\section{Linkage Analysis}

Univariate, multipoint, variance components linkage analysis was performed in MERLIN (Abecasis et al., 2002), with sex and age specified as covariates. Linkage on the $\mathrm{X}$ chromosome was similarly analysed, but using the companion program to MERLIN, MINX (Abecasis, 2004). Within this variance components framework, the QTL effect is estimated using the probabilities that sibling pairs share none, one or both their genes at that locus identical by descent (IBD; calculated using the Lander-Green algorithm with sparse gene flow trees). The QTL 
effect is estimated within a model which incorporates the influence of residual additive polygenic effects and unique environment on the trait. The MZ option in MERLIN enables both members of an MZ pair to be included in the analysis with their non-twin sibling/s. Parameter estimates are derived using maximum likelihood, with the significance of the QTL effect evaluated by the difference in $\log _{10}$ likelihood of a model which includes the QTL and a model which fixes it to zero. This produces a logarithm-of-odds (LOD) score that is compatible with the parametric linkage analysis index.

Linkage was considered significant if LOD scores exceeded 3.6 and suggestive if LOD scores exceeded 2.2 - these criteria have been deemed appropriate for genome-wide linkage for non-replication study designs (Lander and Kruglyak, 1995), but may be highly conservative (Wiltshire et al., 2002). To check the appropriateness of these criteria for our data, empirically derived LOD scores were established for various measures using MERLIN simulation. For each selected variable, 1000 gene-dropping simulations were performed, in which the same phenotypes but newly generated genotypes with the same allele frequencies, marker spacing and missing data pattern were used. As linkage peaks in each simulated genome-scan are due to chance alone, the number of observed false positives per simulation can be obtained for different LOD thresholds (e.g., $\mathrm{LOD}=1, \mathrm{LOD}=2, \mathrm{LOD}=3$ ) and then averaged across all simulations. The regression of these log transformed averages on the respective LOD threshold enables the calculation of the empirical LOD score for suggestive linkage (corresponding to one expected false positive per genome scan) and significant linkage (one expected false positive per 20 genome scans) (Kruglyak and Daly, 1998). However, due to the multiple testing of phenotypes, the suggestive and significance levels were calculated using a Bonferroni correction to the expected number of false positives based on the number of orthogonal factors derived from a principal components analysis of the measures (excluding the scaled scores which are linear derivatives of the subtest scores). While for small values (e.g., 0.05) the expected number of false positives approximates the genomewide significance level, it was necessary to transform the suggestive false positive criterion (i.e., 1) into a probability using the equation $P=1-\mathrm{e}^{-\mu(T)}$, where $P=$ the genome-wide significance level and $\mu T=$ the expected number of false positives (Lander and Kruglyak, 1995). The probability was Bonferroni corrected and then transformed back into a threshold for the expected number of false positives for use in the regression equation. Simulations were not performed for the sex chromosome.

As MERLIN and MINX operate under the assumption of Haldane map locations, the Kosambi map units (derived from the deCODE map) were transformed to Haldane units prior to analysis, although they are back transformed to Kosambi units for reporting of the results.

\section{RESULTS}

\section{Descriptive Analyses}

Phenotype heritabilities (ranging from 0.46 for Spatial to 0.85 for full IQ) estimated in MERLIN encompass the unmodelled effects of shared environment (including additive genetic variance due to assortative mating) and are thus higher than the heritabilities previously reported for the larger sample from which this genotyped sub-sample was drawn (see Table I for previous estimates). Table I shows the range, mean, and standard deviation of each of the measures and the magnitude of the sex and age effects where significant. Sex effects on means were observed for all measures, except vocabulary and the reading tests, with males showing increased scores for all IQ measures but digit symbol. Age effects were present for arithmetic, vocabulary, object assembly and the reading tests, with older participants generally performing better than younger participants.

Inter-correlations among the variables are shown in Table II. Correlations were generally stronger within each of the verbal and performance IQ scales than between them, although digit symbol (from the WAIS-R) and arithmetic showed similar sized correlations with verbal and performance subtests. The reading tests were more strongly correlated with verbal than performance subtests. Verbal and performance IQ scale scores were correlated at 0.53 , and their respective correlations with the reading tests were 0.67 and 0.38 . The principal components analysis of the six IQ subtests and two reading tests revealed two orthogonally rotated factors, explaining $38 \%$ and $27 \%$ of variance (see Table II). The first factor loaded most strongly on the verbal subtests, while the second factor loaded most strongly on the MAB performance IQ subtests.

\section{Linkage Analysis}

Genome-wide linkage results are shown in Figure 1 as plots defined by the LOD score on the 
Table I. Heritabilities $\left(h^{2}\right)$ and Descriptive Statistics for Each of the Measures, Including Mean Differences Between Female and Male Scores (Sex) and the Unstandardised Regression Coefficient for Age (Age)

\begin{tabular}{|c|c|c|c|c|c|}
\hline & Range & Mean $( \pm \mathrm{SD})$ & $\operatorname{Sex} \S$ & Age & $h^{2 *}$ \\
\hline \multicolumn{6}{|l|}{ Verbal subtests } \\
\hline Information $(N=841)$ & $5-38$ & $21(5.6)$ & 1.5 & ns & 0.55 \\
\hline Arithmetic $(N=839)$ & $5-20$ & $12(2.8)$ & 1 & 0.49 & 0.51 \\
\hline Vocabulary $(N=830)$ & $3-32$ & $18(4.7)$ & ns & 0.82 & 0.48 \\
\hline \multicolumn{6}{|l|}{ Performance subtests } \\
\hline Spatial $(N=843)$ & $1-50$ & $31(9.1)$ & 3 & ns & 0.57 \\
\hline Object assembly $(N=842)$ & $3-20$ & $13(3.7)$ & 1 & 0.41 & 0.59 \\
\hline Digit symbol $(N=795)$ & $28-93$ & $60(10.9)$ & $8.1^{\S}$ & ns & 0.65 \\
\hline MAB verbal IQ $(N=840)$ & $81-143$ & $111(11.2)$ & 3.3 & ns & 0.62 \\
\hline MAB performance IQ $(N=842)$ & $68-150$ & $112(16.2)$ & 5.6 & ns & 0.67 \\
\hline MAB Full IQ $(N=840)$ & $81-148$ & $113(12.9)$ & 4.8 & $\mathrm{~ns}$ & 0.69 \\
\hline Cambridge $(N=783)$ & $8-52$ & $32(8)$ & ns & 1.21 & 0.54 \\
\hline Schonell $(N=784)$ - transformed $^{\dagger}$ & $0.3-1.9$ & $1.08(0.3)$ & ns & -0.06 & 0.65 \\
\hline Raw & $22-99$ & $85.52(11.7)$ & & 2.01 & \\
\hline
\end{tabular}

Note: ns - not significant.

*Estimates from Luciano et al. (2004b) and Wainwright et al. (2004), (2005), and are from models in which common environmental effects are also estimated.

${ }^{\dagger}$ Reverse, $\log$ transformed values.

${ }^{\S}$ Sex differences are in the direction of a male advantage for all variables except Digit Symbol.

$y$-zaxis and the position of each of the markers along the $x$-axis. Using a genome-wide threshold for significant linkage of 3.6 (Lander and Kruglyak, 1995), linkage peaks in the same region on the long arm of chromosome 2 (2q24-q31) were significant for performance IQ (peak LOD score of 3.68) and the Cambridge reading test (peak LOD score of 4.15), while other tests (spatial, object assembly, full IQ, Schonell) also showed linkage peaks in this region although their LOD scores fell between 1.53 and 2.14 (see Fig. 2). Of these measures, empirical significance levels were calculated for performance IQ, full IQ, Cambridge reading, and Schonell reading with respective LOD scores of 3.82, 3.52, 4.14, and 3.75 indicating significant linkage, and scores of 2.43, 2.24, 2.60 and 2.40 indicating suggestive linkage.

Suggestive linkage, using the a priori criterion of LOD $>2.2$, was indicated on the short and long arms of chromosome 6 for the respective arithmetic and Schonell reading variables (see Fig. 2), with further suggestive linkage for these variables found on chromosomes 14 and 21 (arithmetic) and 14 and 22 (Schonell). There was also suggestive linkage for vocabulary on chromosome 11 and verbal IQ on chromosome 7. Empirical significance and suggestive significance levels for arithmetic were estimated at respective LOD scores of 3.31 and 2.10. However, no further linkage regions were implicated for arithmetic

Table II. Phenotypic Inter-correlations $(N=771-842)$ Among the Verbal and Performance IQ Subtests and Reading Measures. Factor Loadings are Presented for the Two Orthogonal Factors Derived from a Principal Components Analysis

\begin{tabular}{|c|c|c|c|c|c|c|c|c|c|}
\hline & \multicolumn{7}{|c|}{ Correlations } & \multicolumn{2}{|c|}{ Principal components } \\
\hline & Information & Arithmetic & Vocabulary & Spatial & Object assembly & Digit symbol & Cambridge & $\begin{array}{l}\text { Factor } 1 \\
\text { (Verbal) }\end{array}$ & $\begin{array}{c}\text { Factor } 2 \\
\text { (Performance) }\end{array}$ \\
\hline Information & & & & & & & & 0.75 & 0.34 \\
\hline Arithmetic & 0.49 & & & & & & & 0.43 & 0.56 \\
\hline Vocabulary & 0.66 & 0.42 & & & & & & 0.79 & 0.24 \\
\hline Spatial & 0.36 & 0.42 & 0.29 & & & & & 0.11 & 0.86 \\
\hline Object Ass. & 0.43 & 0.43 & 0.38 & 0.58 & & & & 0.22 & 0.82 \\
\hline Digit symbol & 0.26 & 0.28 & 0.25 & 0.21 & 0.26 & & & 0.26 & 0.38 \\
\hline Cambridge & 0.64 & 0.44 & 0.61 & 0.32 & 0.38 & 0.29 & & 0.87 & 0.20 \\
\hline Schonell & 0.63 & 0.46 & 0.63 & 0.32 & 0.38 & 0.30 & 0.84 & 0.88 & 0.20 \\
\hline
\end{tabular}

Note: All correlations are significant at the 0.01 level. 


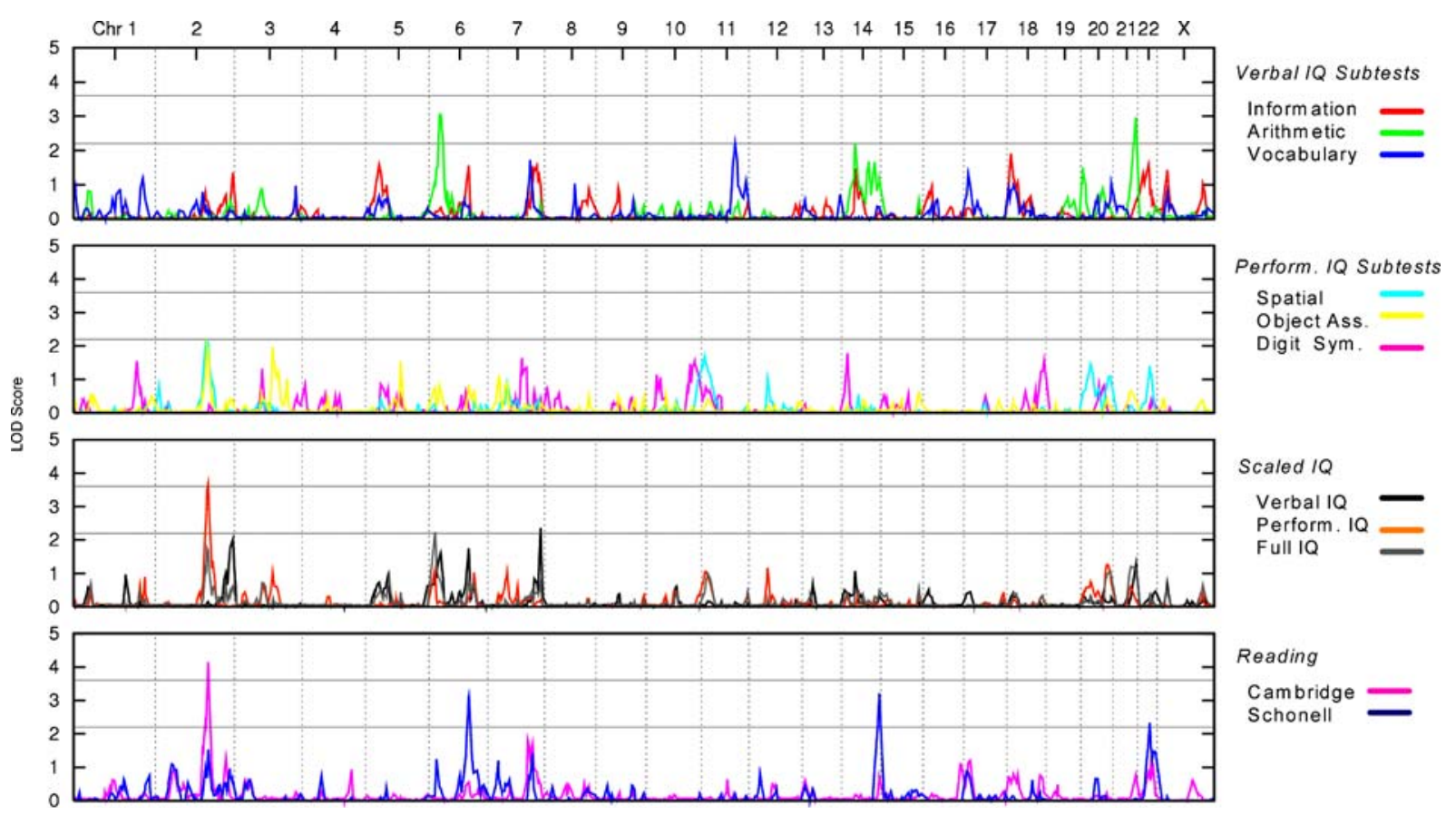

Fig. 1. Linkage plots displaying the significance (LOD score) of the verbal IQ subtests, performance IQ subtests, scale IQ scores, and reading tests to regions on Chromosomes 1 to $23(\mathrm{X})$. LOD scores of 3.6 and 2.2 were adopted as the respective genome-wide significance and suggestive significance levels and are indicated by the horizontal bars, but note the empirical $p$-values for significant linkage for the following variables (LOD score in brackets): performance IQ (3.82), verbal IQ (3.08), full IQ (3.52), Cambridge reading (4.14), Schonell reading (3.75), vocabulary (3.15), and arithmetic (3.31).

by using these lower $p$-value cut-offs. Empirical $p$-values for verbal IQ and vocabulary were also lower than the adopted criteria, with significance linkage indicated by respective LOD scores of 3.08 and 3.15, and suggestive linkage indicated by a LOD score of 2.01. With these lower criteria, suggestive linkage was supported for verbal IQ on chromosome 2 (LOD score of 2.01) at $258.19 \mathrm{cM}$.

While not reaching the criterion for suggestive significance a number of variables showed linkage peaks (LOD score $>1.10$ ) in the same region. On chromosome 7 (130.7-169.87 cM), there was overlap in the linkage signal for information, vocabulary, and the two reading tests. On the short arm of chromosome $6(20.5 \mathrm{cM})$, the linkage peaks overlapped for arithmetic and Schonell reading, while on the long arm $(129.9 \mathrm{cM})$ the linkage peaks for information and Schonell reading converged. Two verbal IQ measures (information, arithmetic) showed overlapping linkage peaks on chromosome $14(40.76 \mathrm{cM})$, and vocabulary and Cambridge reading showed weak linkage to the short arm of chromosome 17 $(10.3 \mathrm{cM})$. On chromosome 22 , in the region spanning $37.03-42.26 \mathrm{cM}$, linkage peaks were observed for both reading tests, spatial ability and information.
Chromosomal regions in which suggestive or significant linkage was indicated, including the range of the cM position defining each peak (and their marker names) are displayed in Table III.

\section{DISCUSSION}

This genome-wide linkage study of IQ is one of the first (see also Posthuma et al., 2005) ever undertaken and shows some promising results, with suggestive/significant linkage indicated for seven (i.e., vocabulary, arithmetic, verbal IQ, performance IQ, full IQ, Cambridge and Schonell reading) of the 11 cognitive measures investigated, some in overlapping chromosomal regions. Not only was consistency in linkage regions supported between the diverse, correlated measures of IQ, but regions that appear-at this stage - to be specific to various tests were also observed. These findings are thus in agreement with genetic covariance studies of IQ subtests (e.g., Martin and Eaves, 1977; Petrill et al., 1996a; Rijsdijk et al., 1998; Wainwright et al., 2004) which find significant influence of general and specific genes in explaining cognitive measure variability. 

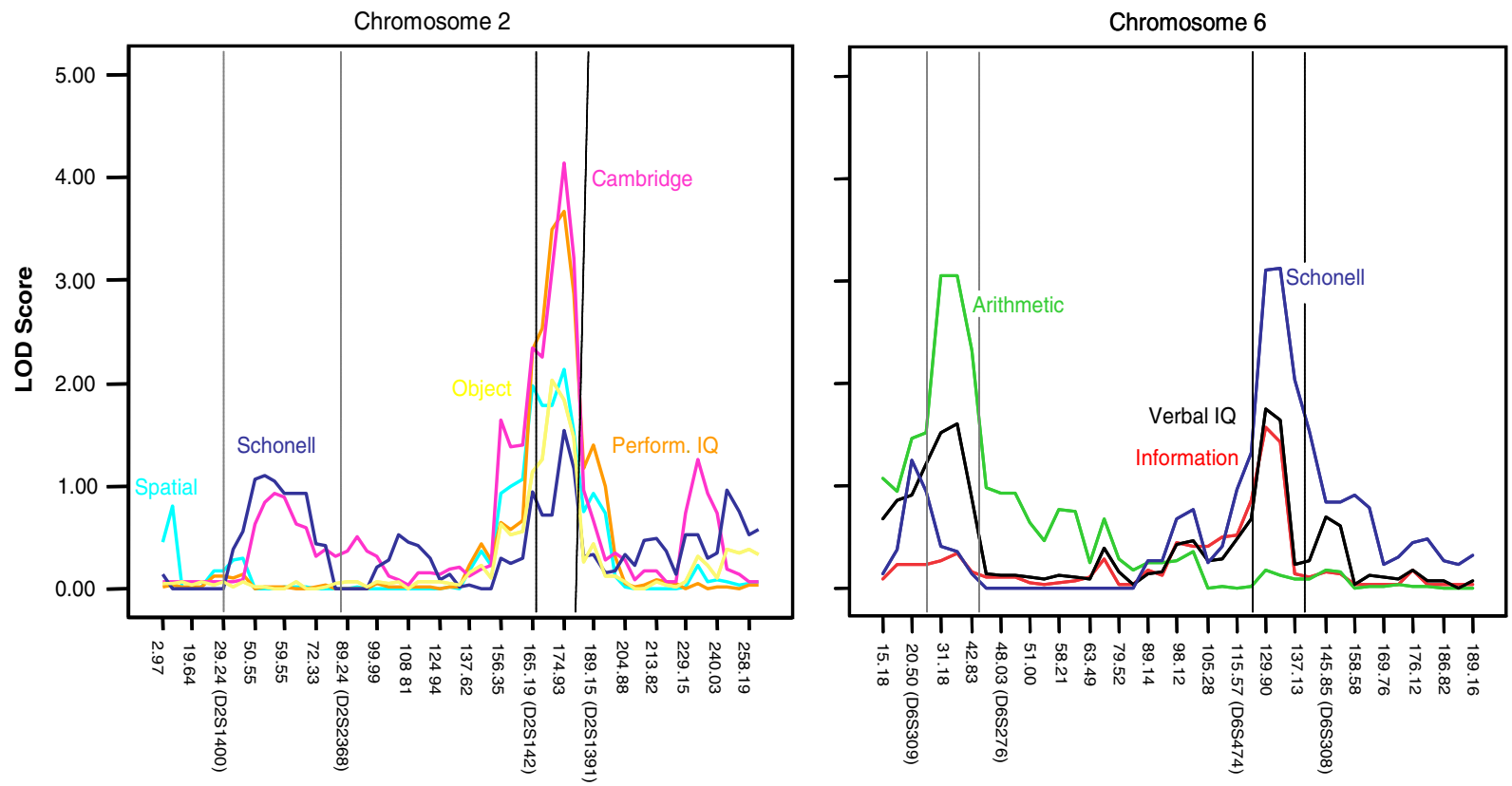

Position (cM)

Fig. 2. Linkage plots for variables showing converging linkage in regions (vertical bars approximate the LOD-1 drop interval from the peak marker) on chromosomes 2 and 6. On the short arm of chromosome 2 small peaks are present for the reading tests, but not the IQ tests (suggesting a reading specific gene), whereas on $2 \mathrm{q}$ both reading and IQ tests peak in the same region (suggesting a general cognitive ability gene). On the long arm of chromosome 6 there is a convergence of linkage for various verbal test measures, and a strong linkage signal on $6 \mathrm{p}$ is present for arithmetic.

In contrast to association studies, which require comparatively small sample sizes to attain sufficient power to detect genes of small effect, linkage analysis has far less power to detect genes of such magnitude. While we expected our linkage analysis to be under- powered, a region on chromosome 2 (165.19$189.15 \mathrm{cM}$ ) was shown to be significantly related to a number of cognitive measures. It is possible that multiple QTLs of small effect underlie this significant linkage, and this has been supported in studies of

Table III. Regions of Significant (LOD>3.6) and Suggestive (LOD>2.2) Linkage for the IQ Measures. The Peak LOD Score for Each Region and Its Empirically Derived Significance Value is Shown Along with Candidate Genes Found Within the Region

\begin{tabular}{|c|c|c|c|c|c|c|}
\hline Chromosome & Variable & Region & cM Range & Peak LOD & Empirical $p$-value* & Candidate Genes \\
\hline \multirow[t]{2}{*}{2} & Cambridge reading test & D2S2313-D2S335 & $156.35-177.98$ & 4.15 & 0.02 & GAD1, NOSTRIN, \\
\hline & Performance IQ & D2S142-D2S1391 & $165.19-189.15$ & 3.68 & 0.03 & $\begin{array}{l}\text { KCNH7, TBR1, } \\
\text { DLX1 DLX2 }\end{array}$ \\
\hline \multirow[t]{3}{*}{6} & Full IQ & D6S1574-D6S309 & $15.18-20.50$ & 2.24 & 0.31 & Neuritin 1 \\
\hline & Arithmetic - verbal subtest & D6S470-D6S422 & $23.75-42.83$ & 3.05 & 0.05 & SSADH \\
\hline & Schonell reading test & D6S287-D6S1009 & $119.55-138.76$ & 3.13 & 0.07 & PNR \\
\hline 7 & Verbal IQ & D7S798-D7S3058 & $169.87-174.29$ & 2.36 & 0.17 & HTR5A \\
\hline 11 & Vocabulary—verbal subtest & D11S898-D11S908 & $103.59-116.46$ & 2.20 & 0.20 & $\begin{array}{r}\text { HTR3A, HTR3B, } \\
\text { DRD2, GRIA4 }\end{array}$ \\
\hline \multirow[t]{2}{*}{14} & Arithmetic - verbal subtest & D14S599-D14S288 & $36.71-44.0$ & 2.21 & 0.26 & - \\
\hline & Schonell reading test & D14S1426-D14S292 & $114.86-122.82$ & 3.21 & 0.06 & - \\
\hline 21 & Arithmetic — verbal subtest & D21S266-D21S1446 & $56.0-73.2$ & 2.97 & 0.05 & S100B \\
\hline 22 & Schonell reading test & D22S689-D22S685 & $32.92-38.79$ & 2.33 & 0.33 & $\begin{array}{l}\text { YWAH, LARGE, } \\
\text { synapsin III }\end{array}$ \\
\hline
\end{tabular}

Note: Marker cM positions are derived from the deCODE map.

*Estimated by counting the number of LOD scores (across 1000 simulations) equal to or exceeding the obtained peak LOD score; these are not adjusted for multiple testing of phenotypes. 
mice where, for instance, a locus influencing anxiety was shown to be composed of three regions, with $\operatorname{Rgs} 2$ identified in one of these regions as a modulator of anxiety (Yalcin et al., 2004). The linkage region implicated in our study was most significant for the Cambridge Contextual Reading Test and performance IQ, although empirical $p$-values indicated reduced linkage to performance IQ. Other measures that showed linkage (albeit non-significant) in this region were the performance subtests, spatial and object assembly, full IQ and Schonell reading, suggesting a general influence of a gene/s in this region on cognitive ability. While linkage to this region was not supported for digit symbol, this is not surprising given the lower correlations between digit symbol with all other measures. However, the lack of a strong linkage signal in this region for the verbal IQ subtests is somewhat puzzling as reading and verbal IQ subtests are strongly correlated; furthermore, it is unlikely that a group factor should influence the reading tests and performance IQ, but not verbal IQ (see Wainwright et al., 2004). It is notable that converging linkage peaks for information and vocabulary were observed around this region $(156.35-165.19 \mathrm{cM})$ and it is possible that a consistent random effect or sampling/test bias present among the MAB verbal IQ subtests negatively affected linkage to this region.

The LOD score for performance IQ on chromosome 2 was higher than that for either spatial or object assembly subtests, of which it is composed. In contrast, the LOD scores for full IQ were lower than those for the MAB performance IQ subtests because the MAB verbal IQ subtests did not show strong evidence of linkage to this region thus weakening the QTL signal for full IQ. These findings are perfectly aligned with the simulations of Martin and colleagues (1997) which showed that in the case of multiple measures affected by the same QTL the use of the mean value of the measures increases power for linkage, whereas use of the mean value will reduce power when not all measures are influenced by the QTL. This effect was further demonstrated in our study within the IQ scales, where suggestive linkage was indicated on $6 \mathrm{p}$ for arithmetic, but weakened evidence was observed for verbal IQ because information and vocabulary were not linked to this region. The implication, then, is that QTL studies - such as the genome-wide association studies of Plomin and colleagues (2001) - that focus only on conglomerate measures such as full IQ (or general ability) or even scaled scores may overlook QTLs that have particularly strong influences on group factors of intelligence or specific test factors. In the present study, several chromosomal regions were identified in which linkage peaks for verbal subtests/reading overlapped, providing support for genetic influence on a verbal group factor (for instance, information, vocabulary, and both reading tests showed linkage peaks in the same region on chromosome 7). Test specific genetic effects were best demonstrated by digit symbol which was the least correlated with the other measures and correspondingly showed the most divergent pattern of linkage from the other measures.

As the reading tests are known to share reading specific variance (although this is smaller than that shared with IQ), it was hypothesised that they might show linkages in regions that have been confirmed in dyslexic samples. A small peak on $6 p$ near a well-known region (6p22) for dyslexia genes was shown for the Schonell, with its peak LOD score (1.24) reaching the significance level suggested for replication (Lander and Kruglyak, 1995). The Cambridge test did not show linkage to this region, but unlike the Schonell test, the Cambridge test has no regular words (those that can be decoded using grapheme-phoneme conversion rules). Phonemic reading may be influenced to a larger extent by QTLs in region $6 \mathrm{p}$ than is orthographic coding or whole word reading required for irregular words. While orthographic coding has been shown to be linked to this region (e.g., Gayan et al., 1999), the Cambridge test differs from orthographic coding tests used to assess dyslexia in that it contains low frequency irregular words to tap IQ. Although there was a discrepancy in the linkage findings for our two reading tests on $6 \mathrm{p}$, consistent and larger peaks were shown in a region $(7 \mathrm{q} 32-\mathrm{q} 34)$ found significant in a Finnish cohort (Kaminen et al., 2003), with the peak LOD score for the Cambridge (1.82) being for the same marker (D7S530) reported in the Finnish study. Another peak in common to the Schonell and Cambridge tests, but not the IQ test measures, was on the short arm of chromosome 2 , but this region was $\sim 25 \mathrm{Mb}$ upstream from an area (2p16-p15) previously confirmed for dyslexia phenotypes (Fagerheim et al., 1999; Petryshen et al., 2002). However, it is known that linkage peaks for true QTLs can vary significantly in location due to a number of mainly stochastic factors (Roberts et al., 1999).

Half of the observed linkage peaks spanned chromosomal regions of around $20 \mathrm{cM}$, making them 
quite large to screen for candidate genes. Nonetheless, a brief bioinformatics search under the linkage peaks identified a number of genes with known or putative function involving regulation of synaptic transmission and plasticity, including neurotransmitter release and excitability. On the long arm of chromosome 2, GAD1, NOSTRIN, KCNH7, TBR1, DLX1 and DLX2, were identified for their role in brain function, with several of these genes involved in glutamanergic neural transmission (which is theorised to influence prefrontal cortex functioning; Huntsman et al., 1998). Some of these genes (GAD1, DLX1 \& 2, TBR1) have been tested for their association with autism, which is linked to this same region of chromosome 2 (Bacchelli et al., 2003; Rabionet et al., 2004). While association was not supported for autism, it is possible that these genes play a role in cognitive ability. In a sample of children and adolescents with childhood-onset schizophrenia, GAD1 was shown to be associated with rate of frontal grey matter loss, which may also relate to the poorer cognitive performance exhibited by those with childhood-onset schizophrenia (Addington et al., 2004).

On chromosome 6, where a number of linkages were found, several candidate genes were apparent. Full IQ showed suggestive linkage to a relatively small region $(\sim 5 \mathrm{cM})$ on the short arm of the chromosome in which Neuritin1, a gene expressed in the postmitotic-differentiating neurons of the developing nervous system and in neuronal structures related to long term plasticity, is located (Naeve et al., 1997). Also on 6p (6p22.3-6p24.3) was a linkage to arithmetic, which is in a nearby region to a recent association of the succinate-semialdehyde dehydrogenase gene (on 6p22) to IQ (Plomin et al., 2004). A combined linkage and association analysis of the SCA1 (Spinocerebellar Ataxia 1; 6p23) gene has been performed in a subsample from this study, with results favouring the influence of QTLs in linkage disequilibrium with SCA1 rather than variants at SCA1 itself accounting for variance in arithmetic performance (Luciano et al., in preparation). The Schonell reading test showed linkage on $6 \mathrm{q}$, with a putative neurotransmitter receptor located in this region (Zeng et al., 1998).

Serotonin, dopamine and glutamate receptor genes were located on chromosome 11 underneath the linkage peak for vocabulary, and a serotonin receptor gene (HTR5A) on chromosome 7 where verbal IQ showed suggestive linkage. While serotonin and dopamine have been primarily implicated in personality and addiction, there has been a suggestion that nicotine can increase memory and learning, with recent animal work confirming nicotine's effect on serotonin and dopamine neurotransmitters (Singer et al., 2004). Other candidate genes were found for the linkages on chromosomes 21 and 22, including S100B, YWHAH, LARGE, and synapsin III, which are all involved in synaptic plasticity, transmission or myelination. Of these, YWHAH and synapsin III have been tested for association with schizophrenia, with some support for association of YWHAH in a Japanese sample (Toyooka et al., 1999), while synapsin III has largely been dismissed as a functional QTL for schizophrenia (e.g., Stober et al., 2000).

Whilst candidate genes could be found under most of our linkage peaks, it would be premature to test these for association without first replicating these linkages in another sample or at the very least in an increased sample size (we are continuing to accrue families). As so many statistical tests were carried out, albeit on correlated measures, it is likely that some of the observed peaks are false positives. However, the empirical significance levels, calculated for seven measures and adjusted for multiple testing, were very similar to the LOD score criteria applied to the remaining variables, and in the case of arithmetic, vocabulary, verbal IQ and full IQ empirical p-values were less stringent. A full genome screen for IQ has been conducted in a Dutch sample of larger age range and their results are compared with those obtained here (see Posthuma et al., 2005); furthermore, the Australian and Dutch data have been combined to successfully increase the power for linkage.

\section{ACKNOWLEDGMENTS}

We should like to thank the twins and their parents for their co-operation, Manuel Ferreira and Sarah Medland for assistance with data simulations and linkage analysis, Anjali Henders for blood processing and Megan Campbell for DNA extraction. Phenotype collection was funded by ARC grants (A79600334, A79906588, A79801419, DP0212016, DP0343921) and genotyping by the Australian NHMRC's Program in Medical Genomics (NHMRC -219178) and the Center for Inherited Disease Research (CIDR; Director, Dr Jerry Roberts) at The Johns Hopkins University. CIDR is fully funded through a federal contract from the National Institutes of Health to The Johns Hopkins University 
(Contract Number N01-HG-65403). Dr Luciano is supported by an Australian Research Council Postdoctoral Fellowship (DP0449598).

\section{REFERENCES}

Abecasis, G. R. (2004). http://www.sph.umich.edu/csg/abecasis/ Merlin/reference.html

Abecasis, G. R., Cherney, S. S., Cookson, W. O., and Cardon, L. R. (2002). Merlin-rapid analysis of dense genetic maps using sparse gene flow trees. Nat. Genet. 30:97-101.

Addington, A. M., Gornick, M., Duckworth, J., Sporn, A., Gogtay, N., Bobb, A., Greenstein, D., Lenane, M., Gochman, P., Baker, N., Balkissoon, R., Vakkalanka, R. K., Weinberger, D. R., Rapoport, J. L., and Straub, R. E. (2004). GAD1 (2q31.1), which encodes glutamic acid decarboxylase $(\mathrm{GAD}(67))$, is associated with childhood-onset schizophrenia and cortical gray matter volume loss. Mol. Psychiatry. Advance online publication 26 October.

Bacchelli, E., Blasi, F., Biondolillo, M., Lamb, J. A., Bonora, E., Barnby, G., Parr, J., Beyer, K. S., Klauck, S. M., Poustka, A., Bailey, A. J., Monaco, A. P., and Maestrini, E. (2003). Screening of nine candidate genes for autism on chromosome $2 \mathrm{q}$ reveals rare nonsynonymous variants in the cAMP-GEFII gene. Mol. Psychiatry 8:916-924.

Beardsall, L., and Huppert, F. A. (1994). Improvement in NART word reading in demented and normal older persons using the Cambridge Contextual Reading Test. J. Clin. Exp. Neuropsychol. 16:232-242.

Cardon, L. R., Smith, S. D., Fulker, D. W., and Kimberling, W. J., et al., (1994). Quantitative trait locus for reading disability of chromosome 6. Science 266:276-279.

Carroll, J. B. (1993). Human Cognitive Abilities: A Survey of Factor-Analytic Studies. Cambridge: Cambridge University Press.

Casto, S. D., DeFries, J. C., and Fulker, D. W. (1995). Multivariate genetic analysis of Wechsler Intelligence Scale for Children Revised (WISC-R) factors. Behav. Genet. 25:25-32.

Cattell, R. B. (1963). Theory of fluid and crystallized intelligence: a critical experiment. J. Educ. Psychol. 54:1-22.

Chorney, M. J., Chorney, K., Seese, N., Owen, M. J., Daniels, J., McGuffin, P., Thompson, L. A., Detterman, D. K., Benbow, C., Lubinski, D., Eley, T., and Plomin, R. (1998). A quantitative trait locus associated with cognitive ability in children. Psychol. Sci. 9:1-8.

De Koning, D. J., Visscher, P. M., Knott, S. A., and Haley, C. S. (1998). A strategy for QTL detection in half-sib populations. Anim. Sci. 67:257-268.

Fagerheim, T., Raeymaekers, P., Tonnessen, F. E., Pedersen, M., Tranebjaerg, L., and Lubs, H. A. (1999). A new gene (DYX3) for dyslexia is located on chromosome 2. J. Med. Genet. 36:664-669.

Fisher, S. E., Francks, C., Marlow, A. J., MacPhie, I. L., Newbury, D. F., Cardon, L. R., Ishikawa-Brush, Y., Richardson, A. J., Talcott, J. B., Gayan, J., Olson, R. K., Pennington, B. F., Smith, S. D., DeFries, J. C., Stein, J. F., and Monaco, A. P. (2002). Independent genome-wide scans identify a chromosome 18 quantitative-trait locus influencing dyslexia. Nat. Genet. 30:86-91.

Gayan, J., Smith, S. D., Cherney, S. S., Cardon, L. R., Fulker, D. W., Brower, A. M., Olson, R. K., Pennington, B. F., and DeFries, J. C. (1999). Quantitative-trait locus for specific language and reading deficits on chromosome 6p. Am. J. Hum. Genet. 64:157-164.

Gustafsson, J.-E. (1984). A unifying model for the structure of intellectual abilities. Intelligence 8:179-203.
Horn, J. L., and Cattell, R. B. (1966). Refinement and test of the theory of fluid and crystallized general intelligences. J. Educ. Psychol. 57:253-270.

Huntsman, M. M., Tran, B. V., Potkin, S. G., Bunney, W. E. Jr., and Jones, E. G. (1998). Altered ratios of alternatively spliced long and short gamma2 subunit mRNAs of the gamma-amino butyrate type A receptor in prefrontal cortex of schizophrenics. Proc. Natl. Acad. Sci. USA. 95:15066-15071.

Jackson, D. N. (1984). Manual for the Multidimensional Aptitude Battery. Port Huron, MI: Research Psychologists Press.

Jackson, D. N. (1998). Multidimensional Aptitude Battery II. Port Huron, MI: Sigma Assessment Systems, Inc.

Kaminen, N., Hannula-Jouppi, K., Kestila, M., Lahermo, P., Muller, K., Kaaranen, M., Myllyluoma, B., Voutilainen, A., Lyytinen, H., Nopola-Hemmi, J., and Kere, J. (2003). A genome scan for developmental dyslexia confirms linkage to chromosome $2 \mathrm{p} 11$ and suggests a new locus on 7q32. J. Med. Genet. 40:340-345.

Kong, A., Gudbjartsson, D. F., Sainz, J., Jonsdottir, G. M., Gudjonsson, S. A., Richardsson, B., Sigurdardottir, S., Barnard, J., Hallbeck, B., Masson, G., Shlien, A., Palsson, S. T., Frigge, M. L., Thorgeirsson, T. E., Gulcher, J. R., and Stefansson, K. (2002). A high-resolution recombination map of the human genome. Nat. Genet. 31:241-247.

Kruglyak, L., and Daly, M. J. (1998). Linkage thresholds for two-stage genome scans. Am. J. Hum. Genet. 62:994-997.

Lander, E., and Kruglyak, L. (1995). Genetic dissection of complex traits: guidelines for interpreting and reporting linkage results. Nat Genet. 11:241-247.

Leal, S. M. (2003). Genetic maps of microsatellite and single-nucleotide polymorphism markers: are the distances accurate? Genet. Epidemiol. 24:243-252.

Legare, M. E., Bartlett, F. S. II., and Frankel, W. N. (2000). A major effect QTL determined by multiple genes in epileptic EL mice. Genome. Res. 10:42-48.

Luciano, M., Hine, E. J., Wright, M. J., Duffy, D. L., and Martin, N. G. (in preparation). Combined linkage and association tests of SCA1, MJD and DPRLA triplet repeat polymorphisms with cognitive phenotypes in a normal population of adolescent twins.

Luciano, M., Wright, M. J., Geffen, G. M., Geffen, L. B., Smith, G. A., Evans, D. M., and Martin, N. G. (2003). A genetic twofactor model of the covariation among a subset of Multidimensional Aptitude Battery and WAIS-R subtests. Intelligence 31:589-605.

Luciano, M., Wright, M. J., Geffen, G. M., Geffen, L. B., Smith, G. A., and Martin, N. G. (2004a). A genetic investigation of the covariation among inspection time, choice reaction time, and IQ subtest scores. Behav. Genet. 34:41-50.

Luciano, M., Wright, M. J., and Martin, N. G. (2004). Exploring the etiology of the association between birthweight and IQ in an adolescent twin sample. Twin. Res. 7:62-71.

Martin, N. G., Boomsma, D. I., and Machin, G. A. (1997). A twinpronged attack on complex traits. Nat. Genet. 17:87-392.

Martin, N. G., and Eaves, L. J. (1977). The genetical analysis of covariance structure. Heredity 38:79-95.

McClearn, G. E., Johansson, B., Berg, S., Pederson, N. L., Ahern, F., Petrill, S. A., and Plomin, R. (1997). Substantial genetic influence on cognitive abilities in twins 80 or more years old. Science 276:1560-1563.

Naeve, G. S., Ramakrishnan, M., Kramer, R., Hevroni, D., Citri, Y., and Theill, L. E. (1997). Neuritin: a gene induced by neural activity and neurotrophins that promotes neuritogenesis. Proc. Natl. Acad. Sci. USA. 94:2648-2653.

Nelson, H. E. (1982). National Adult Reading Test. Berkshire: NFER Nelson Publishing Company.

Pedersen, N. L., Plomin, R., and McClearn, G. E. (1994). Is there a $\mathrm{G}$ beyond $\mathrm{g}$ ? (Is there genetic influence on specific cognitive 
abilities independent of genetic influence on general cognitive ability?). Intelligence 18:133-145.

Petrill, S. A., Luo, D., Thompson, L. A., and Detterman, D. K. (1996a). The independent prediction of general intelligence by elementary cognitive tasks: genetic and environmental influences. Behav. Genet. 26:135-147.

Petrill, S. A., Plomin, R., McClearn, G. E., Smith, D. L., Vignetti, S., Chorney, M. J., Chorney, K., Thompson, L. A., Detterman, D. K., Benbow, C., Lubinski, D., Daniels, J., Owen, M. J., and McGuffin, P. (1996b). DNA markers associated with general and specific cognitive abilities. Intelligence 23:191-203.

Petryshen, T. L., Kaplan, B. J., Hughes, M. L., Tzenova, J., and Field, L. L. (2002). Supportive evidence for the DYX3 dyslexia susceptibility gene in Canadian families. J. Med. Genet. 39:125-126.

Plomin, R. (1999). Genetics and general cognitive ability. Nature 402: $\mathrm{C} 25-\mathrm{C} 29$.

Plomin, R., Hill, L., Craig, I. W., McGuffin, P., Purcell, S., Sham, P. C., Thompson, L. A., Fisher, P. J., Turic, D., and Owen, M. J. (2001). A genome-wide scan of 1842 DNA markers for allelic associations with general cognitive ability: a five-stage design using DNA pooling and extreme selected groups. Behav. Genet. 31:497-509.

Plomin, R., McClearn, G. E., Smith, D. L., Skuder, P., Vignetti, S., Chorney, M. J., Chorney, K., Kasarda, S., Thompson, L. A., Detterman, D. K., Petrill, S. A., Daniels, J., Owen, M. J., and McGuffin, P. (1995). Allelic associations between 100 DNA markers and high versus low IQ. Intelligence 21:31-48.

Plomin, R., McClearn, G. E., Smith, D. L., Vignetti, S., Chorney, M. J., Chorney, K., Venditti, C. P., Kasarda, S., Thompson, L. A., Detterman, D. K., Daniels, J., Owen, M., and McGuffin, P. (1994). DNA markers associated with high versus low IQ: the IQ quantitative trait loci (QTL) project. Behav. Genet. 24:107-118.

Plomin, R., Turic, D. M., Hill, L., Turic, D. E., Stephens, M., Williams, J., Owen, M. J., and O'Donovan, M. C. (2004). A functional polymorphism in the succinate-semialdehyde dehydrogenase (aldehyde dehydrogenase 5 family, member A1) gene is associated with cognitive ability. Mol. Psychiatry 9:582-586.

Posthuma, D., Luciano, M., Geus, E. J. d., Wright, M. J., Slagboom, E., Montgomery, G. W., Boomsma, D. I., and Martin N. G. (submitted). A genome-wide scan for IQ in two independent samples identifies quantitative trait loci on $2 \mathrm{q}$ and $6 \mathrm{p}$. Am. J. Hum. Genet.

Rabionet, R., Jaworski, J. M., Ashley-Koch, A. E., Martin, E. R., Sutcliffe, J. S., Haines, J. L., Delong, G. R., Abramson, R. K., Wright, H. H., Cuccaro, M. L., Gilbert, J. R., and PericakVance, M. A. (2004). Analysis of the autism chromosome 2 linkage region: GAD1 and other candidate genes. Neurosci. Lett. 372:209-214.

Rietveld, M. J. H., van Baal, C., Dolan, C. V., and Boomsma, D. I. (2000). Genetic factor analyses of specific cognitive abilities in 5-year-old Dutch children. Behav. Genet. 30:29-40.

Rijsdijk, F. V., Vernon, P. A., and Boomsma, D. I. (1998). The genetic basis of the relation between speed-of-informationprocessing and IQ. Behav. Brain Res. 95:77-84.

Roberts, S. B., MacLean, C. J., Neale, M. C., Eaves, L. J., and Kendler, K. S. (1999). Replication of linkage studies of complex traits: an examination of variation in location estimates. Am. J. Hum. Genet. 65:876-884.

Rujescu, D., Hartmann, A. M., Gonnermann, C., Moller, H. J., and Giegling, I. (2003). M129V variation in the prion protein may influence cognitive performance. Mol. Psychiatry 8:937-941.

Singer, S., Rossi, S., Verzosa, S., Hashim, A., Lonow, R., Cooper, T., Sershen, H., and Lajtha, A. (2004). Nicotine-induced changes in neurotransmitter levels in brain areas associated with cognitive function. Neurochem. Res. 29:1779-1792.

Spelman, R. J., Coppieters, W., Karim, L., van Arendonk, J. A., and Bovenhuis, H. (1996). Quantitative trait loci analysis for five milk production traits on chromosome six in the Dutch Holstein-Friesian population. Genetics 144:1799-1808.

SPSS (1989-2003). SPSS 12.0.2 for Windows. SPSS Inc.

Stober, G., Meyer, J., Nanda, I., Wienker, T. F., Saar, K., Knapp, M., Jatzke, S., Schmid, M., Lesch, K. P., and Beckmann, H. (2000). Linkage and family-based association study of schizophrenia and the synapsin III locus that maps to chromosome 22q13. Am. J. Med. Genet. 96:392-397.

Toyooka, K., Muratake, T., Tanaka, T., Igarashi, S., Watanabe, H., Takeuchi, H., Hayashi, S., Maeda, M., Takahashi, M., Tsuji, S., Kumanishi, T., and Takahashi, Y. (1999). 14-3-3 protein eta chain gene (YWHAH) polymorphism and its genetic association with schizophrenia. Am. J. Med. Genet. 88:164-167.

Tsai, S. J., Hong, C. J., Yu, Y. W., and Chen, T. J. (2004). Association study of a brain-derived neurotrophic factor (BDNF) Val66Met polymorphism and personality trait and intelligence in healthy young females. Neuropsychobiology 49:13-16.

van Wezel, T., Ruivenkamp, C. A., Stassen, A. P., Moen, C. J., and Demant, P. (1999). Four new colon cancer susceptibility loci, Scc6 to Scc9 in the mouse. Cancer Res. 59:4216-4218.

Vink, J. M., and Boomsma, D. I. (2002). Gene finding strategies. Biol. Psychol. 61:53-71.

Wainwright, M. A., Wright, M. J., Geffen, G. M., Geffen, L. B., Luciano, M., and Martin, N. G. (2004). Genetic and environmental sources of covariance between reading tests used in neuropsychological assessment and IQ subtests. Behav. Genet. 34:365-376.

Wainwright, M. A., Wright, M. J., Geffen, G. M., Luciano, M., and Martin, N. G. (2005). The genetic basis of academic achievement on the Queensland Core Skills Test and its shared genetic variance with IQ. Behav. Genet. 35:133-145.

Ward, L. C., Ryan, J. J., and Axelrod, B. N. (2000). Confirmatory factor analyses of the WAIS-III standardization data. Psychol. Assess. 12:341-345.

Wiltshire, S., Cardon, L. R., and McCarthy, M. I. (2002). Evaluating the results of genomewide linkage scans of complex traits by locus counting. Am J Hum Genet 71:1175-1182.

Wright, M. J., De Geus, E., Ando, J., Luciano, M., Posthuma, D., Ono, Y., Hansell, N. K., Van Baal, C., Hiraishi, K., Hasegawa, T., Smith, G., Geffen, G., Geffen, L., Kanba, S., Miyake, A., Martin, N., and Boomsma, D. (2001). Genetics of cognition: outline of collaborative twin study. Twin Res. 4:48-56.

Yalcin, B., Willis-Owen, S. A., Fullerton, J., Meesaq, A., Deacon, R. M., Rawlins, J. N., Copley, R. R., Morris, A. P., Flint, J., and Mott, R. (2004). Genetic dissection of a behavioral quantitative trait locus shows that Rgs 2 modulates anxiety in mice. Nat. Genet. 36:1197-1202.

Zeng, Z., Fan, P., Rand, E., Kyaw, H., Su, K., Madike, V., Carter, K. C., and Li, Y. (1998). Cloning of a putative human neurotransmitter receptor expressed in skeletal muscle and brain. Biochem. Biophys. Res. Commun. 242:575-578.

Zhu, G., Duffy, D. L., Eldridge, A., Grace, M., Mayne, C., O'Gorman, L., Aitken, J. F., Neale, M., Hayward, N. K., Green, A. C., and Martin, N. G. (1999). A major quantitative-trait locus for mole density is linked to the familial melanoma gene CDKN2A: a maximum-likelihood combined linkage and association analysis in twins and their sibs. Am. J. Hum. Genet. 65:483-492.

Zhu, G., Evans, D. M., Duffy, D. L., Montgomery, G. W., Medland, S. E., Gillespie, N. A., Ewen, K. R., Jewell, M., Liew, Y. W., Hayward, N. K., Sturm, R. A., Trent, J. M., and Martin, N. G. (2004). A genome scan for eye color in 502 twin families: most variation is due to a QTL on chromosome 15q. Twin Res. 7:197-210.

Edited by Danielle Posthuma 